\title{
Bluestem Gall Midge Annual Production Cycle and Effects on Grass Seed Production
}

\author{
Earle S. Raun ${ }^{1 *}$, Robert B. Mitchell2\# \\ ${ }^{1}$ Pest Management Co., Lincoln, NE, USA \\ ${ }^{2}$ USDA-ARS, Wheat, Sorghum, and Forage Research Unit, 251 Filley Hall UNL EC, University of Nebraska, Lincoln, NE, USA \\ Email: ${ }^{*}$ rob.mitchell@a rs.usda.gov
}

How to cite this paper: Raun, E.S. and Mitchell, R.B. (2018) Bluestem Gall Midge Annual Production Cycle and Effects on Grass Seed Production. American Journal of Plant Sciences, 9, 2077-2085. https://doi.org/10.4236/ajps.2018.910151

Received: August 14, 2018

Accepted: September 25, 2018

Published: September 28, 2018

Copyright ( 92018 by authors and Scientific Research Publishing Inc. This work is licensed under the Creative Commons Attribution International License (CC BY 4.0).

http://creativecommons.org/licenses/by/4.0/

\section{c) (i) Open Access}

\begin{abstract}
The bluestem gall midge (Stenodiplosis wattsii Gagné) is native to the grasslands of North America. It feeds on the developing seeds of warm-season grasses during a portion of its lifecycle, but little is known of the biology and extent of gall midge infestations in native warm-season grasses in the USA. We investigated the infestations of the bluestem gall midge in big bluestem (Andropogon gerardii Vitman), sand bluestem (Andropogon gerardii var paucipilus), little bluestem [Schizachyrium scoparium (Michx.) Nash], and indiangrass [Sorghastrum nutans (L.) Nash] commercial seed production fields during 2001 through 2004. Our objectives were to determine the annual production cycle of the bluestem gall midge, the range of the infestation in Nebraska, and estimate its impact on seed production. In eastern Nebraska, the midge goes through four generations with the fourth entering a larval diapause, overwintering in seeds and emerging in mid-June of the following year. The bluestem gall midge damaged from $31 \%$ of the little bluestem seed to $67 \%$ of the big bluestem seed, and, on average, reduced the production of viable seed by $54 \%$ across the four grass species in eastern Nebraska. Additionally, the warm-season prairie grasses were surveyed in nine other counties in Nebraska and the bluestem gall midge was found in each species surveyed from all nine counties. This study is the first to document the negative effects of the bluestem gall midge on the production of viable seed in sand bluestem and indiangrass.
\end{abstract}

\section{Keywords}

Life History, Seed Midge, Seed Predation, Stenodiplosis wattsii

\section{Introduction}

The bluestem gall midge (Stenodiplosis wattsii Gagné) is native to the tallgrass *deceased. 
prairie of North America and has been identified in several native warm-season grasses in the USA [1]. During a portion of its lifecycle, it feeds on the developing caryopses of perennial warm-season grasses. The reduced seed production due to midge infestation had little historic impact on native grassland persistence since most native perennial grasses maintain their stands primarily by asexual reproduction. Commercial seed production from native grasses became prominent in the USA after the drought of the 1930's and became profitable during conservation programs such as the Soil Bank and Conservation Reserve Program, which brought the midge to the attention of seed producers in the USA. Currently, commercial seed producers of warm-season prairie grasses are concerned that insect damage may be reducing viable seed yields in seed production fields.

The bluestem gall midge was originally described in little bluestem [Schizachyrium scoparium (Michx.) Nash] [2] as Contarinia wattsii Gagné, but the species has been reclassified as Stenodiplosis wattsii Gagné [3]. However, it is interesting to note that Cornelius [4] reported the larvae of an insect infested 10 to $20 \%$ of big bluestem (Andropogon gerardii Vitman) florets but attempts to identify the larvae were unsuccessful. He reported the larvae resembled the caryopses of big bluestem, were filled with an orange-colored liquid, and resembled the sorghum midge (Contarinia sorghicola). Cornelius was apparently the first to document the negative effects of the bluestem gall midge on seed production.

Little information has been published on this insect. Carter et al. [5] identified infestations of a seed midge in big bluestem in eastern Nebraska, USA. They reported three generations of the bluestem gall midge occurred each year, with the third generation entering diapause. They estimated seed loss could exceed $40 \%$.

Vogel and Manglitz [6] reviewed the effect of the bluestem gall midge on the sexual reproduction of big bluestem. They speculated that other warm-season grasses are likely infested by the midge but collected no specimens from other grasses. They indicated that no information is available on many aspects of the life history and biology of the bluestem gall midge and this lack of information limits our understanding of the need for control. Additionally, they discussed similar midges occurring in the seeds of smooth bromegrass (Bromus inermis Leyss.), timothy (Phleum pratense L.), and sorghum [Sorghum bicolor (L.) Moench].

Boe et al. [7] reported that seed set in big bluestem was reduced by the bluestem gall midge. They reported infestation of sessile spikelets was greater than for pedicellate spikelets. Consequently, the pedicellate spikelet trait increased total seed set in the presence of the bluestem seed midge and may have potential for improving seed yields.

Vogel and Manglitz [8] applied the insecticides Furadan (2,3-dihydro-2,2dimethyl-7-benzofuranyl methylcarbamate) and Orthene (O,S-Dimethyl acetylphosphoramidothioate) to control the bluestem gall midge in big bluestem seed production fields. They reported that midges were present in the treated and 
non-treated areas, and application of the insecticides did not significantly reduce bluestem gall midge numbers. However, application of either insecticide increased the processed seed yield of big bluestem.

We initiated a study in Nebraska, USA to quantify the annual production cycle, presence, potential hosts, and potential impact of the bluestem gall midge on seed production in commercial fields of big bluestem, sand bluestem (Andropogon gerardii var paucipilus), little bluestem, and indiangrass [Sorghastrum nutans (L.) Nash]. Our objectives were to: 1) determine the annual production cycle and population demographics of the bluestem gall midge in four native warm-season grasses, 2) determine the frequency of seed predation by the bluestem gall midge, and 3) estimate the geographic range of the bluestem gall midge in Nebraska, USA.

\section{Materials and Methods}

Field and laboratory pilot studies were conducted in 2000 and 2001. Adult midges were collected from "Pawnee" big bluestem, "Goldstrike" sand bluestem, "Camper" little bluestem, and 'Tomahawk' indiangrass and sent to Dr. Raymond J. Gagné at the Systematic Entomology Laboratory, USDA, Washington, DC. He verified the specimens as Stenodiplosis wattsii Gagné.

\subsection{Emergence from Diapause Traps}

Traps like those described by Raatikainen et al. [9] were constructed to collect adult bluestem gall midges emerging from over-wintering sites. Rods were welded at the corners to form a four-sided pyramid with a $51-\mathrm{cm}$ by $51-\mathrm{cm}$ square base. Rods forming the four corners were tapered up 51-cm to the square top to which a metal canning jar ring was welded. The outside of the pyramid was covered with black, water repellant cloth, leaving the square bottom open and the top of the pyramid enclosed with a clear glass jar. The jar was screwed onto the canning jar ring to provide a receptacle for transparent sheets coated with Tangle-Trap ${ }^{\circledast}$ (The Tanglefoot Company, Grand Rapids, MI) insect trap coating.

Beginning in mid-June, two traps were placed in certified seed production fields of big bluestem, sand bluestem, little bluestem, and indiangrass. Seed production fields had been burned earlier in the spring, and traps were placed in areas where accumulated litter remained on the fields. The outside base of each trap was placed over the litter and the base covered with soil, allowing the primary light to be at the top of the funnel. Each week the sheet of Tangle-Trap was removed and replaced with a clean sheet. Emerged midges caught in the Tangle-Trap ${ }^{\circ}$ were sexed, counted with $10 \mathrm{X}$ magnification, and numbers recorded. Number and sex ratios of the bluestem gall midge were collected in 2001, 2002, 2003, and 2004 in Cass County, Nebraska. Data from 2001 were not included since traps were not placed in the fields until an estimated two-thirds of the emergence had already occurred. 


\subsection{Summer Generations}

Twenty inflorescences of big bluestem, sand bluestem, and little bluestem were randomly harvested to leave about $15-\mathrm{cm}$ of stem below the flowers. The inflorescences were bundled together and enclosed in a clear plastic bag. Each bundle was then stored in an upright position at room temperature. Twice each day the clear bags were examined for emerged insects. When insects were present, the bag was placed in a freezer for one minute to inactivate the insects. The specimens were then removed from the bag with a soft camel-hair brush, placed in alcohol, identified under magnification, sorted by species, and stored in vials of alcohol. Midges were sexed and counted under the microscope, and the numbers of each sex were recorded. A new bundle was handled in this way every week, until the seed production field for the grass species was harvested. The same procedures were followed from late July through late September in 2001, 2002, 2003, and 2004. Indiangrass exserted inflorescences two to three weeks before the other species and was not included in the summer emergence evaluation.

\subsection{Diapause Generation and Seed Damage}

Immediately prior to seed harvest, inflorescences were gathered randomly from pace transects in seed production fields of each grass species. Inflorescences were transported to the laboratory, florets removed, and individual florets for each species ( 350 - 800) examined by microscopic dissection. Florets were recorded as fertile, empty (not fertilized), damaged, viable, or infested with a midge larva in diapause.

\subsection{Geographic Range}

During August of 2003, a survey of eight Nebraska counties was conducted to determine the geographic range of the bluestem gall midge in Nebraska. Big bluestem and little bluestem inflorescences were collected from roadsides, set-aside acres, seeded pastures, and native prairies in Butler, Custer, Fillmore, Howard, Kearney, Lincoln, Red Willow, and Thomas Counties in Nebraska, USA. Inflorescences were bagged, location noted, and evaluated daily for midge emergence as previously described.

\section{Results and Discussion}

\subsection{Annual Life Cycle Stages of the Bluestem Gall Midge}

\subsubsection{Emergence of the Diapause Generation}

The emergence traps demonstrated that insect emergence coincided with inflorescence emergence in the earliest flowering warm-season grasses. The first midges caught in the diapause traps each year were in the week of 17 June, with the last midge emerging about 20 July. In 2003, the first inflorescences emerged on 25 June for little bluestem and sand bluestem and on 7 July for big bluestem. The ratio of males to females emerging from diapause was similar each year, with 3.5, 2.8, and 2.6 males per female in 2002, 2003, and 2004, respectively. To- 
tal midges trapped during diapause emergence were 71,316, and 144 in 2002, 2003, and 2004, respectively. The bluestem gall midge is well-adapted to the prairie environment. The midge goes into diapause in late summer and autumn as temperatures decline and day length shortens and remains in diapause through the winter and spring. As sufficient heat accumulates, and days lengthen in late spring and early summer, pupation is initiated, and adults emerge as grass inflorescences exert.

\subsubsection{Summer Generations}

The ratio of males to females during summer generations was variable (Table 1). In 2001 and 2004, the number of emerging male midges was equal to the number of emerging female midges. However, in 2002, 2.6 times more females emerged than males. But in 2003, 2.1 times more males emerged than females. We have no explanation for the variation in sex ratios.

Bluestem gall midge emergence peaked from mid- to late August when averaged across grass species and years from 2001 to 2004 (Figure 1). Emergence approached zero by mid-September. Averaged across four years and nine sampling periods per year, the sex ratio was 1:1.

During 2001 to 2004, four adult generations were present each year, including those that emerged from diapause. They were attracted to the grass flowers and oviposited in pollinated florets. Yellowish larvae hatched from the microscopic eggs, one to a floret. Larvae from eggs laid by the fourth-generation females entered diapause. Tomahawk indiangrass flowered first each year, and attracted the earliest mated females emerging from diapause. Oviposition began immediately in big bluestem, sand bluestem, and little bluestem as inflorescences emerged.

Each larva of the first three generations fed on a developing seed, largely consuming it. Eggs of the fourth generation were laid on florets with partially-developed seeds. This generation fed and went into diapause in the autumn, frequently within the uneaten remains of a developed seed. The 2004 growing season was cooler and wetter than the previous growing seasons, so part of the third generation entered diapause and only a partial fourth generation developed.

\subsubsection{Damage Resulting from Bluestem Gall Midge Infestation}

Gall midge damage to a floret typically resulted in the complete consumption of the endosperm, so a damaged seed would not be viable. Based on all florets

Table 1. Mean number of males and females (standard error of the mean) and sex ratio of Stenodiplosis wattsii emerging from inflorescences collected on nine dates during 2001, 2002, 2003, and 2004 in Cass County, Nebraska, USA.

\begin{tabular}{cccc}
\hline Year & Number of Males & Number of Females & Male: Female Ratio \\
\hline 2001 & $176(9.3)$ & $171(8.8)$ & $1: 1$ \\
2002 & $61(5.6)$ & $156(8.9)$ & $1: 2.6$ \\
2003 & $169(9.0)$ & $77(4.7)$ & $2.2: 1$ \\
2004 & $24(1.6)$ & $20(2.0)$ & $1: 1$ \\
\hline
\end{tabular}




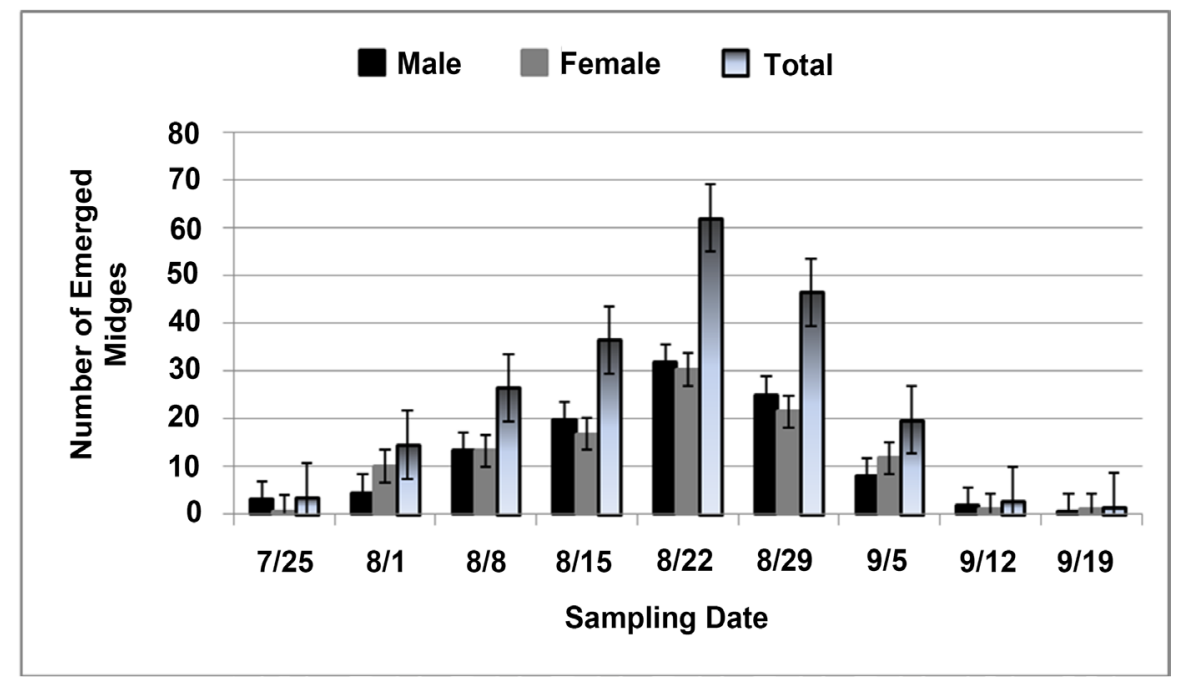

Figure 1. Number of bluestem gall midges emerging from bundles of 20 inflorescences of big bluestem, sand bluestem, and little bluestem collected during 2001, 2002, 2003, and 2004 in Cass County, Nebraska. Inflorescences were collected on the date indicated and evaluated during the next six days to determine midge emergence. Error bars represent the standard error of the mean.

examined, the percentage of fertile florets was $76 \%$ for big bluestem, $65 \%$ for sand bluestem, 93\% for little bluestem, and 45\% for indiangrass (Table 2). Of the fertile florets, the percentage damaged by gall midge activity was $60 \%$ for big bluestem, $51 \%$ for sand bluestem, $47 \%$ for little bluestem, and $56 \%$ for indiangrass. Consequently, the bluestem gall midge damaged more than $50 \%$ of the fertile florets averaged across all four grass species.

\subsubsection{Geographic Range}

Bluestem gall midges emerged from every sample collected in Butler, Custer, Fillmore, Howard, Kearney, Lincoln, Red Willow, and Thomas Counties in Nebraska, USA (Figure 2). Based on our collections and previous literature reports, the bluestem gall midge likely occurs in most areas where big bluestem, little bluestem, indiangrass, and sand bluestem grow in Nebraska, and these grasses likely provide critical habitat for midge reproduction.

\subsection{Other Insects Encountered in Inflorescences}

The weekly bagged inflorescences revealed two other insect species. The most frequently encountered was a grass thrips (Thysanoptera). Four to eight individuals emerged daily during August. Their rasping mouthparts allow feeding on sugars in the plant sap of stems and florets. The other insect occasionally found in bagged inflorescences was Eugaurax floridensis Sabrosky (Diptera: Chloropidae: Oscinellinae). It is apparently the only species of this genus in the USA. The larva is a typical pale-green seed maggot that feeds on grass seed, as does the bluestem gall midge. These were found in only 2 of the 5 years during which these grasses were studied. 
Table 2. Seed characteristics of microscopically examined florets of "Pawnee" big bluestem, "Goldstrike" sand bluestem, "Camper" little bluestem, and "Tomahawk" indiangrass randomly collected from commercial certified seed fields in Cass County, Nebraska, USA. The percent of damaged and viable seed are based on fertile florets. Empty florets were never fertilized.

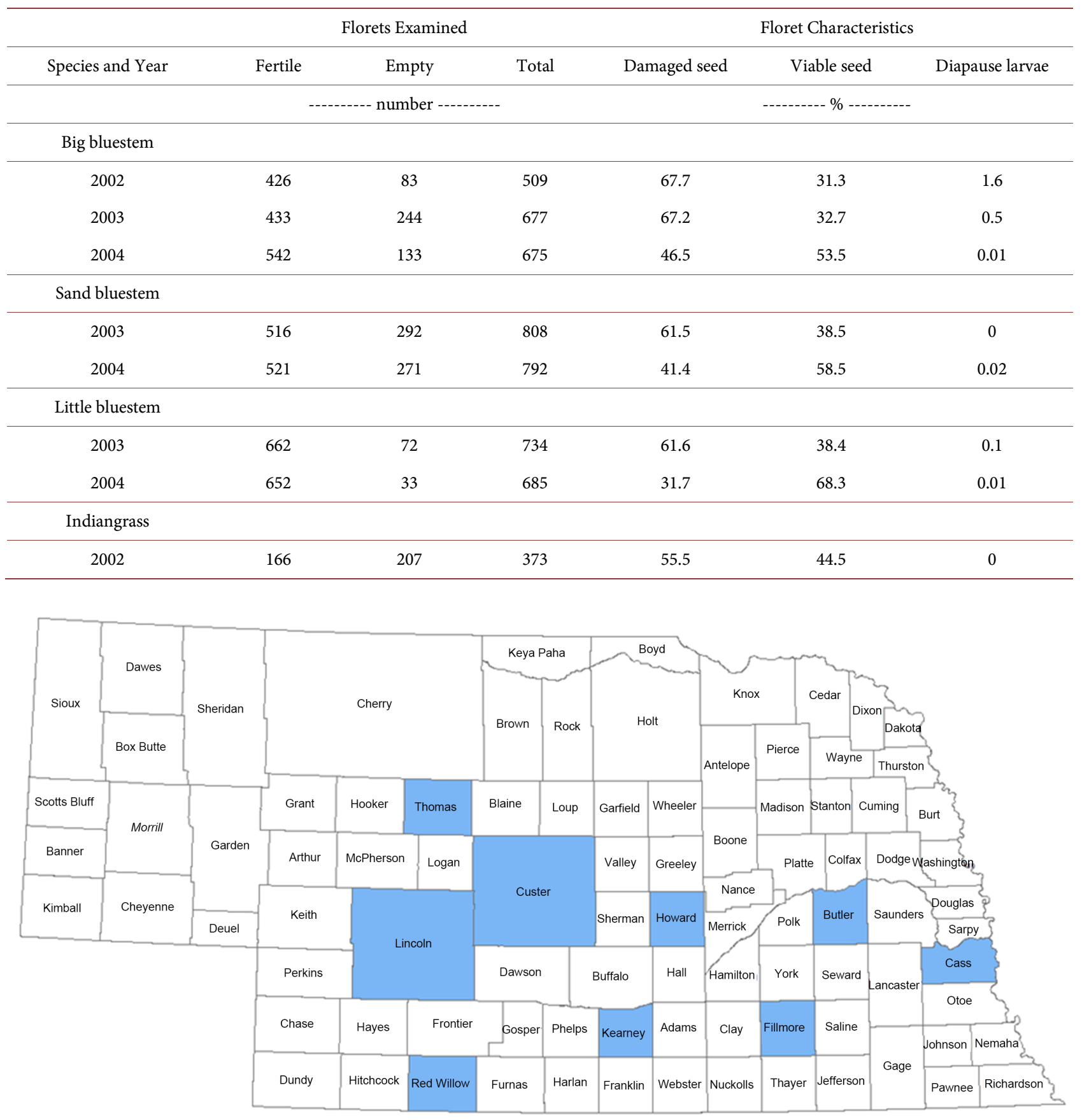

Figure 2. The bluestem gall midge was identified in the inflorescences of native warm-season grasses collected in Butler, Cass, Custer, Fillmore, Howard, Kearney, Lincoln, Red Willow, and Thomas Counties in Nebraska, USA which are identified in blue.

\subsection{Summary and Conclusion}

More than 20,000 florets of big bluestem, sand bluestem, little bluestem, and indiangrass were dissected during this study. The bluestem gall midge was found in four warm-season grass species in eastern Nebraska and in nine counties in 
eastern and central Nebraska. In eastern Nebraska, the midge goes through four generations with the fourth going into a larval diapause, overwintering in seeds which generally have fallen to the ground. The diapausing larva remains in the fallen seed until mid-June of the following year. During 2002, 2003, and 2004, gall midge infestations in untreated certified seed production fields ranged from $67 \%$ in big bluestem to as little as $31 \%$ in little bluestem. Its effects on seed production are of little consequence in native prairie or conservation stands of these grasses. However, the consequences to commercial seed production can be severe. On average, the bluestem gall midge damaged $54 \%$ of the seed in inflorescences of big bluestem, sand bluestem, little bluestem, and indiangrass in eastern Nebraska. Consequently, treatment to control the bluestem gall midge could double the production of viable seed and provide a significant economic benefit to commercial seed producers of these species. Additionally, this study is the first to document the negative effects of the bluestem gall midge on the production of viable seed in sand bluestem and indiangrass.

\section{Acknowledgements}

We thank Stock Seed Farms of Murdock, Nebraska, USA for support and for allowing access to seed production fields during this study. Their cooperation was invaluable. We thank Dr. Raymond J. Gagné at the Systematic Entomology Laboratory, USDA-ARS, Washington DC for his expertise in insect identification. It was an honor to work with Dr. Earle Raun. He was inquisitive and tireless throughout this project and was a true gentleman. The USDA prohibits discrimination on the basis of race, color, national origin, age, disability, and where applicable, sex, marital status, familial status, parental status, religion, sexual orientation, genetic information, political beliefs, reprisal, or because all or part of an individual's income is derived from any public assistance program. Mention of trade names or commercial products in this publication does not imply recommendation or endorsement by the USDA. USDA is an equal opportunity employer. Funding to complete this research was provided by USDA-ARS.

\section{Conflicts of Interest}

The authors declare no conflicts of interest regarding the publication of this paper.

\section{References}

[1] Watts, J.G. and Bellotti, A.C. (1967) Some New and Little-Known Insects of Economic Importance on Range Grasses. Journal of Economic Entomology, 60, 961-963. https://doi.org/10.1093/jee/60.4.961

[2] Gagné, R.J. (1966) The Nearctic Species of Contarinia Which Infest Grasses (Diptera: Cecidomyiidae). The Proceedings of the Entomological Society of Washington, 68, 318-321.

[3] Gagné, R.J. (2004) A Catalog of the Cecidomyiidae of the World. Memoirs of the Entomological Society of Washington, 23, 263. 
[4] Cornelius, D.R. (1950) Seed Production of Native Grasses under Cultivation in Eastern Kansas. Ecological Monographs, 20, 1-29. https://doi.org/10.2307/1943521

[5] Carter, M.R., Manglitz, G.R., Rethwisch, M.D. and Vogel, K.P. (1988) A Seed Midge Pest of Big Bluestem. Journal of Range Management, 41, 253-254. https://doi.org/10.2307/3899180

[6] Vogel, K.P. and Manglitz, G.R. (1989) Effect of the Big Bluestem Seed Midge on the Sexual Reproduction of Big Bluestem: A Review. In: Bragg, T.B. and Stubbendieck, J., Eds., Proceedings of the Eleventh North American Prairie Conference. Prairie pioneers, Ecology, History, and Culture, University Nebraska, Lincoln, 267-291.

[7] Boe, A., Robbins, K. and McDaniel, B. (1989) Spikelet Characteristics and Midge Predation of Hermaphroditic Genotypes of Big Bluestem. Crop Science, 29, 1433-1435. https://doi.org/10.2135/cropsci1989.0011183X002900060020x

[8] Vogel, K.P. and Manglitz, G.R. (1990) Evaluation of Furadan and Orthene against a Bluestem Seed Midge, 1986 and 1987. Insecticide and Acaricide Tests, 15, 175-176.

[9] Raatikainen, M., Savas, O.E. and Timilai, A. (1967) Contarinia kanervoi, Barnes (Dipt. Itonididiae), Bionomics, Damage and Control. Annales Agriculturae Fenniae, 6, 145-158. 